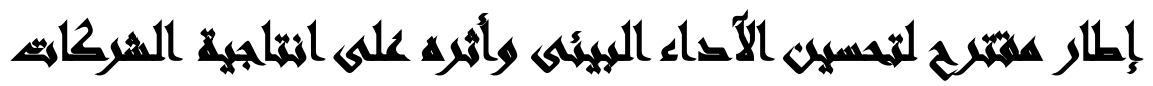 \\ السناعية
}

[11]

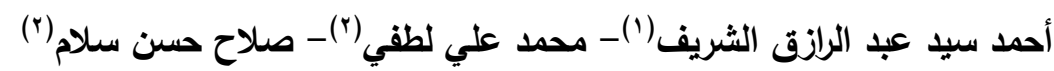

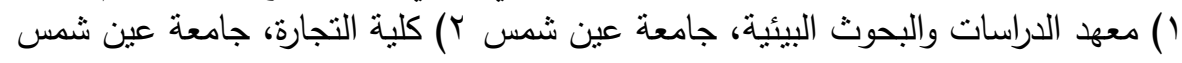

\section{المستخلئ}

استهدف هذه الدراسة إلى التعرف على لتحسين الآداء البيئى وأثره على انتاجية الثركات

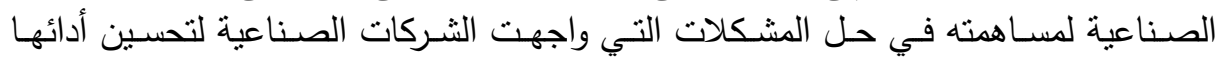
لتحقيق هذا الهدف إعتمد الباحثون على التأصيل النظري من خلال المنهج الإستقرائي،

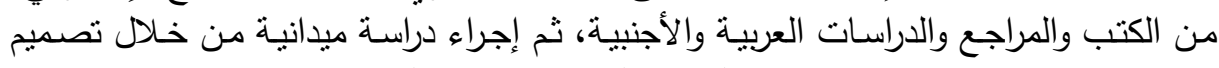

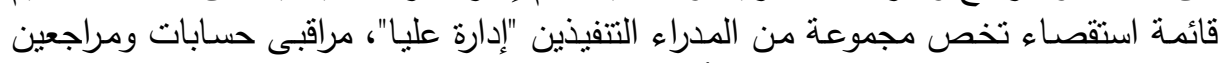
داخلين، وذلك بهدف دراسة ارائهم فى أثر التحسين البيئى على انتاجية الثين الثركات الصناء الصناعية.

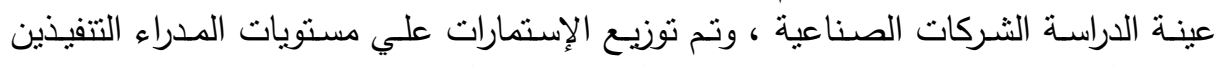

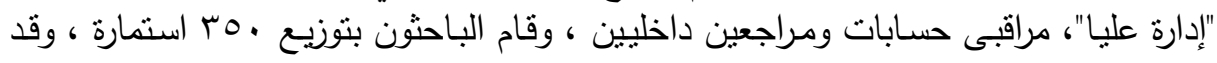

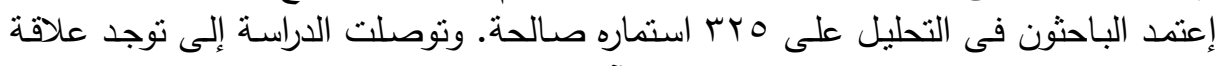

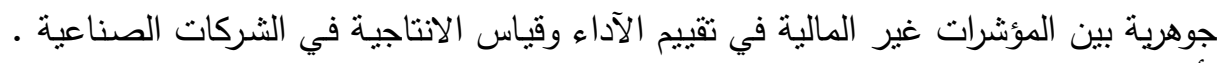

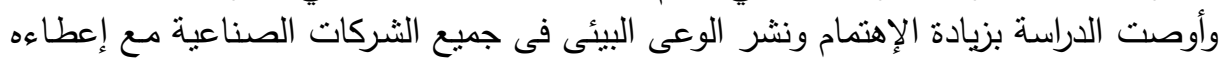

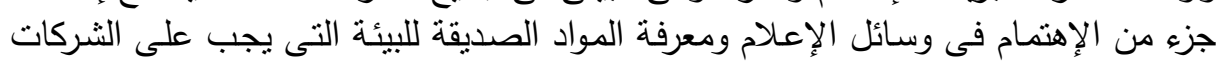
البحث عنها والإقبال عليها.

\section{$\sin$}

تزايد العالم الآونة الأخيرة بالقرن العشرين موضوع الآداء البيئي في الثركات الصناعية، والتي يقصد بها اهنمام المؤسسات والثركات بمصـالح الآداء وتحمل مسئولية الآثار الناجمـة عن نشاطات المؤسسات على الزبائن والعاملين والمـلك والمجتمع والبيئة، وهذه المسئولية لا تقتصر فقط على الإلتزامات القانونية بل تتجاوزها إلى تحسين العلاقة مـع أصحاب المصلحة

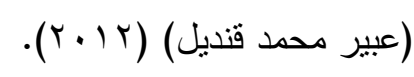


ومن المفروض أن تحسين الآداء البيئي الآداء ضمن الخطط السنوية للمؤسسات بحيث

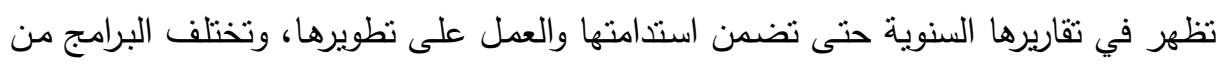
تدريب للعاملين إلى البرامج التعليمية إلى المساهمة في نطوير المتنزهات وتتبجيع المبادرات البيئية والإهتمام بأسر العاملين ودعم المؤسسات الخيرية والشركات الناشئئة.

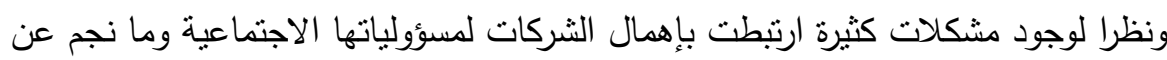

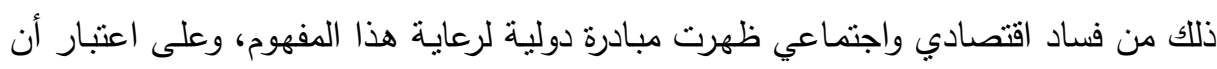
المؤسسات الصناعية من أكثر الأطراف تأثثرا في القطاع الاقتصادي والبيئي، فإن اهتمامها لهابها بهذه المواصفة يعد أمراً حتميا ولازما، فهي مطالبة بالتصرف المسئول تجاه المجتمع والبيئة

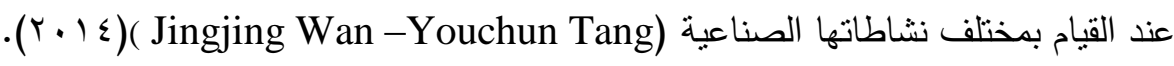

\section{هيمالج الهيه}

يشهـ العالم تغيرات جذرية وعميقة خاصـة في الآداء البيئي للشركات الصناعية ، ومـع تزايد الحاجة وما تتطلبه لتحسين الآداء البيئي والسريع والثشامل ارتفاع عدد الثركات الصناعية لئه

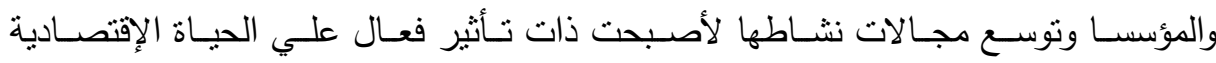

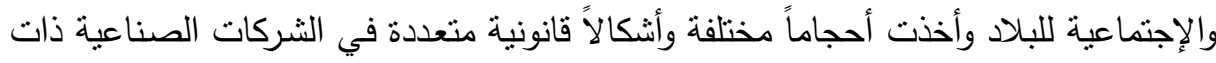

$$
\text { الطابع الصناعي (1 ( . ب)( عمرو حسين عبد البر). }
$$

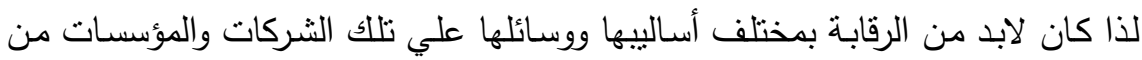

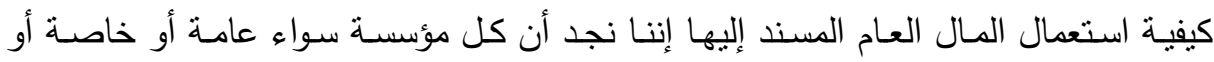
انتاجية حسب طبيعة النشاط الذي تقوم بـه. ويمكن عرض مشكلة الدراسة في سؤال جوهري

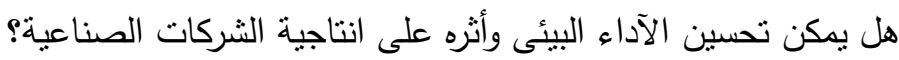
ويستمد من السؤال الرئيسي منه عدة أسئلة فرعية وهي:

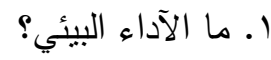
r. ما طبيعة انتاجية الثركات الصناعية؟ ماله

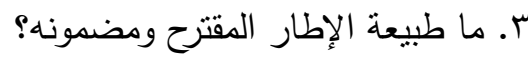




\section{أهساهيت الترواسة}

الهلف الرئيسي للاراسة محاولة وضع إطار مقترح لتحسين الآداء البيئى وأثره على انتاجية

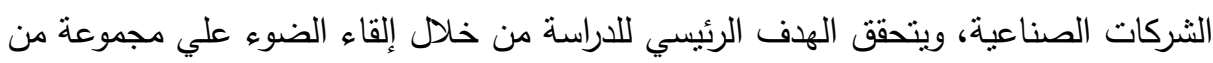

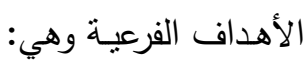
ا ـ التعرف علي الآداء البيئي في الثركات الصناعية. r ب بيان أثز الآداء البيئي علي إنتاجية الثركات الصناءية. r. طبيعة الاطار المقترح ومضمونه.

\section{هغوضر الكراسما}

الفرض الأول : توجد علاقة جوهريـة بين المؤشـرات غير المالية في تقييم الآداء وقياس الانتاجية في الثركات الصناعية. الفرض الثاني: توجد علاقة جوهرية بين الإفصاح عن الأداء البيئي وتحسين الأداء البيئي في الثركات الصناعية.

\section{Aوبs}

إقتصرت الدراسة علي قطاع بعض الثركات الصناعية

\section{منهميد التصواسمة}

تستمد هذه الدراسة أهميتها من الموضوع ومدى ضرورته في الثركات الصناعية وإعتمد الباحث على المنهج الوصفي التحليلي في دراستنا، حيث يعرف هذا المنهج بأنها الطريقة

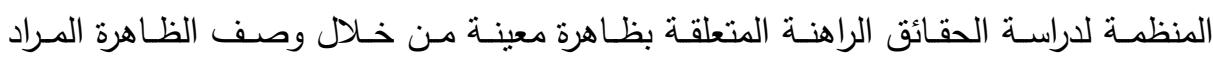

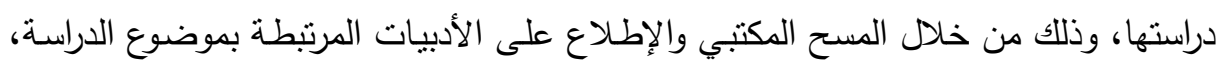
وثم تمت عملية تحليل المعلومات المحصل عليها في سبيل الخروج بنتائج عامة، بالإضافة الإنة إلي تحقيق أهداف الدراسة وإعتمد الباحث علي المنهجين التاليين: 
المنهج الإستقرائي: والذي يعتمد علي الدراسات المكتبية والتي تعتمد علي الكتب والدوريات العربية والأجنبيـة ويتم ذلك من خـلال إطار نظري تستخدم فيه مفاهيم مفهوم الأداء البيئي والإفصاح عنه ، وأيضاً منطلبات تحسين الآداء البيئي الإفصاح عنه ، ومن ثم أنواع الأداء

المنهج الإستتباطي: يقوم الباحثون من خلال هذا المنهج بإختبار الإطار النظري والذي تم

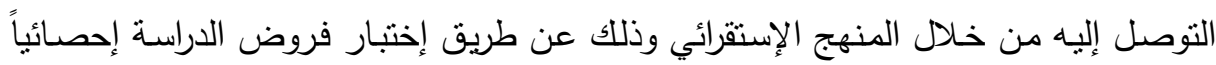
من خلال الدراسة الميدانية.

\section{أهمية القواسمة}

ترجع أهمية الدراسة من خلال محاولة الإدارة للشركات الصناعية علي معرفة الطريقة

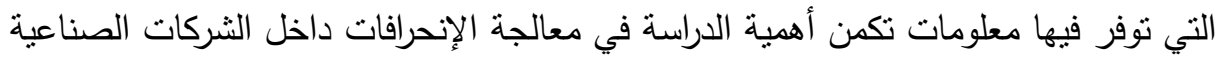
ويعمل على ترشيد الإنفاق وزيادة الانتاجية الكلية والجزئية من خلال إستخدام المنثأة لمواردها المتاحة وتحقيق التتمية المستدامة من خلال تقييم وتحسين الآداء البيئى.

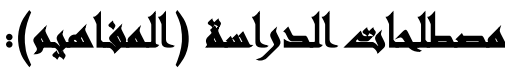

1 - مفهوم الأداء: يعتبر تحديد مفهوم دقيق للأداء من أهم المسائل التى طرحت فى الساحة

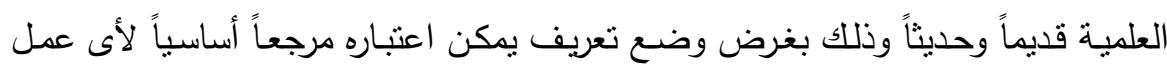

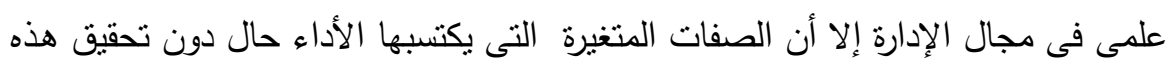

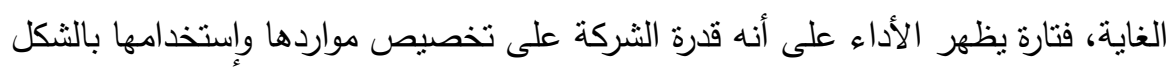

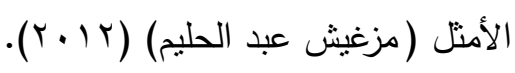

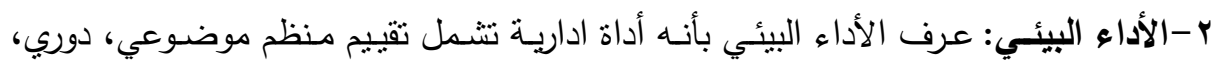

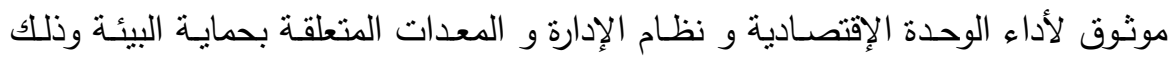

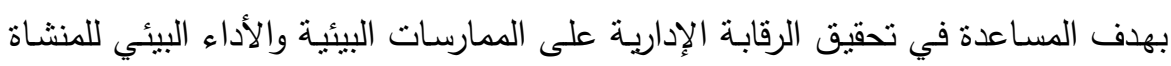

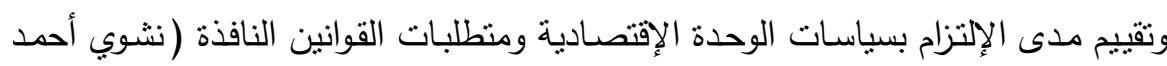


r-متطلبات تحسين الآداء البيئي الإفصاح عنه: أهية وضرورة الإفصاح المحاسبي عن

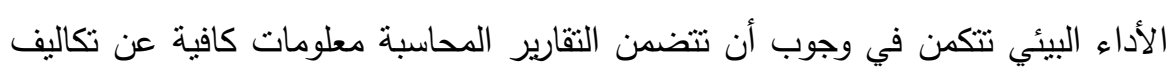

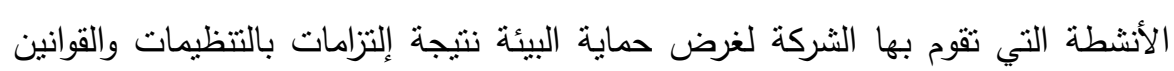

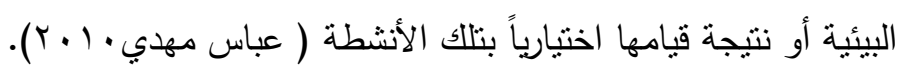

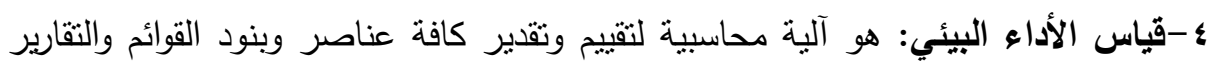

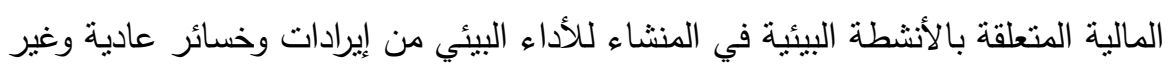

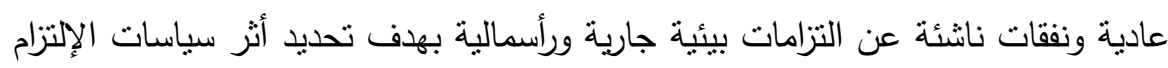

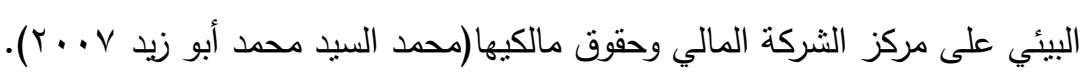

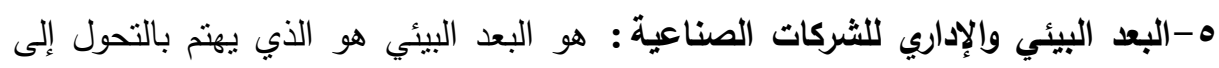

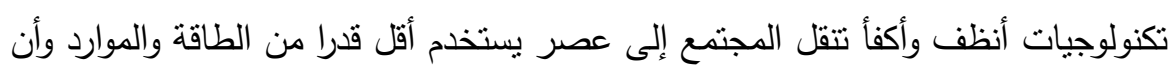
يكون الهدف من هذه النظم التكنولوجية إنتاج حد أدنى من الغازات والملوثات وإستخدام

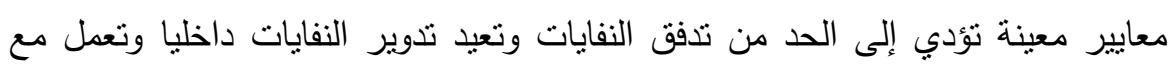

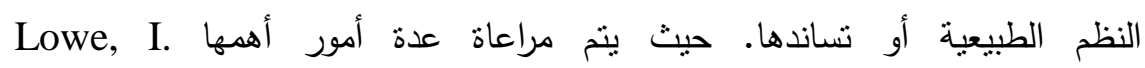
.(2004) (Globalization )

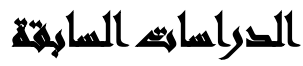 \\ 1- دراسة (Ittner and Larcker 2015) بعنوان:}

"Coming Up Short on Nonfinancial Performance Measurement" تهـدف الدراسـة إلـي التعـرف على مقاييس الأداء المختلفـة التي تستخذمها الثـركات،

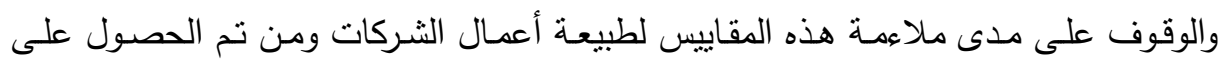
معلومات تقيد في كيفية استخدام المقاييس المختارة. كما أوضحت الدراسة أن الغرض من وجود نظام لقياس وتقييم الأداء هو مساعدة الإدارة

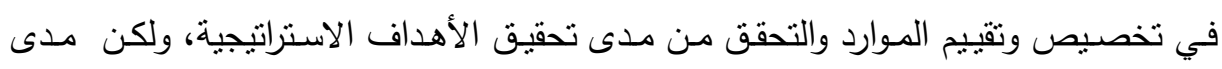

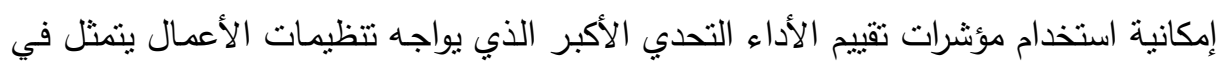
تحديد ما هي المقاييس غير المالية. 
ونتائج الدراسة نتشير إلي أن هناك عدد من الأخطاء العامة التي قد تقع فيها تتظيمات

$$
\begin{aligned}
& \text { الأعمال عند محاولتها قياس الأداء غير المالي تتمنل في: } \\
& \text { • عدم ربط مقاييس الأداء بإستراتيجية نتظيم الأعمال. } \\
& \text { • • استخدام روابط غير صحيحة. } \\
& \text { • • وضع أهداف غير سليمة للأداء. }
\end{aligned}
$$

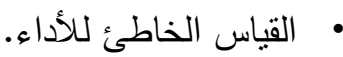

Genevieve Doublet - GydaMjollIngolfsdottir and others دراسة

$$
\text { 2014) بعنوان: }
$$

"Key Environmental Performance Indicators for a simplified LCA in food supply chains"

تهدف الدراسة إلي تنسيط مجموعة المعطيات والمعلومات المطلوبة عن طريق تجميع مؤشرات الأداء البيئى وتعريفاته ومفاهيمية وطرق نطور الاداء البيئي في الشركات الصناعية. ونتائج الدراسة نتير إلي التعرف علي تحليل سلسلة لثلاثة أغذية لتقييم دورة حياة لهاه تأثيراتها من خلال الرعاية الصناعية المتوقعة للكتلة الحيوية (تقييم دورة حياة عصبر البرتقال).

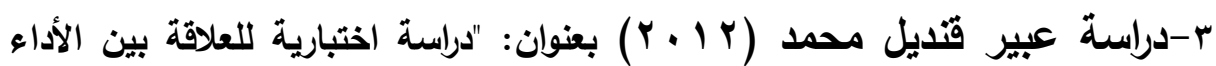
البيئي والإفصاح البيئي في الشركات المساهمة المصرية " تهدف الدراسة إلي تحديد مدي وجود علاقة بين الأداء والإفصاح البيئي في الشركات

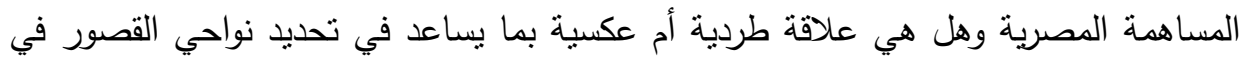

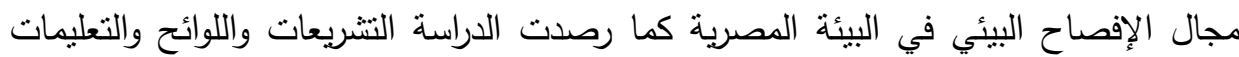
الأزمة لوفير الآليات المناسبة للإفصاح البيأي لئي وكان من أبرز نتائج هذه الدراسة ان غالبية الانشطة والعطليات المرتبطة بالاداء البيئي للثركة لها جوانب مالية ومحاسبية تنعكس اثارها بشكل مباشر أو غير مباشر علي القوائم والتقارير المالية للشركة ومن ثم علي قرارات الاطراف المهتمة ويترتب علي عدم تتفيذ الشركة لادائها البيئي. 


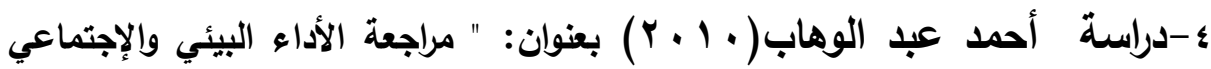

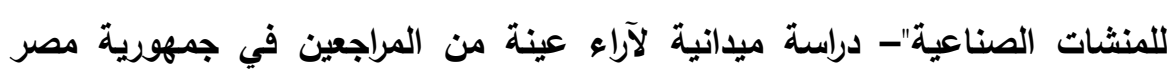

تهدف الدراسة إلي التعرف ينصب اهتمام برامج المراجعة التي يعدها مراجع الحسابات

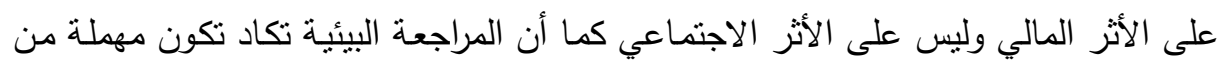

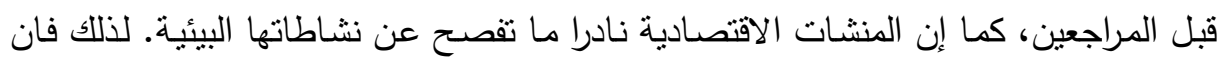

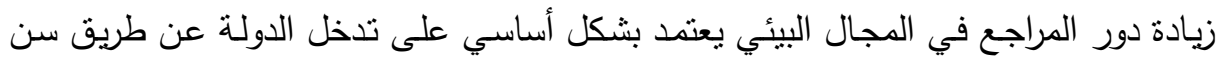

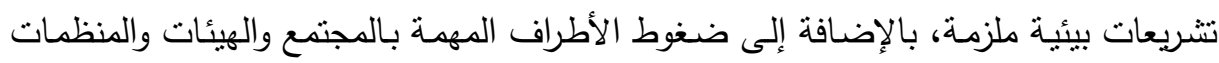
المهنية على المنشات.

نتائج الدراسة تشير إليها هى أن المعايير المحاسبية للإفصاح المحاسبي البيئي أصبحت

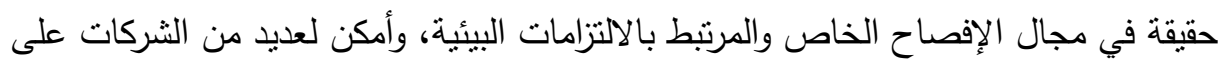

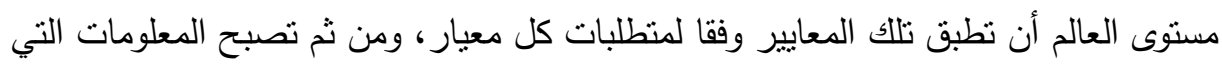
يتم الإفصاح عنها خدمة لأصحاب المصالح المتعارضة أمر في غاية الأهمية لتأثر القرارات الاستثمارية بما تقصح عنه تلك الوحدات الاقتصادية.

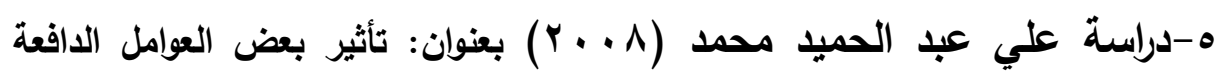
للاستجابة البيئية علي الآداء البيئي والقدرة التنافسية لمنظمات الأعمال الصناعية المصرية " نموذج مقترح"

تهدف الدراسة إلي يتمتل نموذج يتتاول تأثثر محددات الاستجابة البيئية علي الأداء

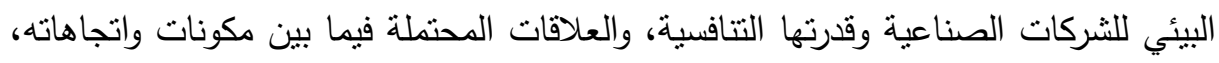
وتستمد هذه الدراسة من أهميتهم من اهتمام الباحثين والممارسين بتقعيل التوجه البيئي للحفاظ

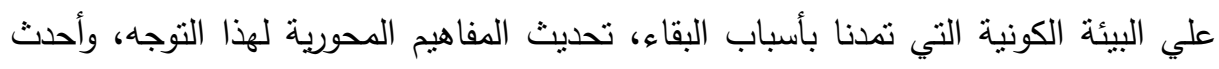
التغيرات للانتقال إلي مرحلة الاستدامة بهدف الحفاظ علي حقوق الاجيال القادمة في التمتع بمستوي معيشي لائق مقارنة بالجيل الحالي. 
ونتائج الدراسة نتشير إلي أهمية لدافعة للاستجابة البيئية للشركات الا انه من التطور الاقتصادي والتغيرات في البيئة المحيطة بالثركات اصبح من الضروري التوسع في نطاقها، وليس هناك إطار عام وشامل العوامل الدافعة، هناك عوامل تؤثثر علي قرار العوامل الدافعة فئن

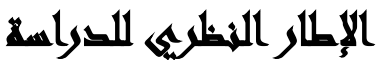

\section{مفهوم الأداء البيئي والإفصاح عنه:}

مفهوم الأداء: اختلف الباحثون في تحديد مفهوم الأداء، وتعود أسباب هذا الاختلاف إلى تعدد واختلاف مؤشرات قياسه وكذلك تباين طبيعة عمل المؤسسات الإقتصادية وأهدافها والجهات

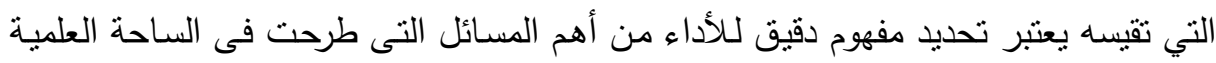

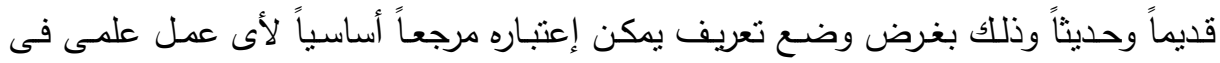

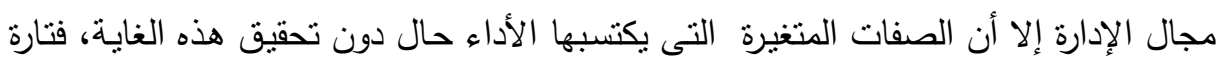
يظهر الأداء على أنه قدرة الثركة على تخصيص مواردها وإستخدامها بالثكل الأمثل، وتارة يرتبط بإنتاجية العمال والعنصر البشرى (مزغيش عبد الحليم) (r أ. r). أنواع الأداء البيئي: بالبه 1 - الإفصــاح الإختبـاري: لا يشترك المستثرون مـع الإدارة الأنشطة اليوميـة للثـركة حيث

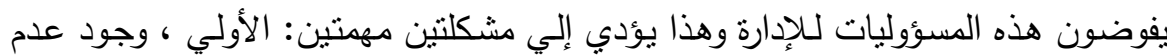
تمانل للمعلومات فإن المستثرين أقل معرفة مقارنة بالإدارة بشأن أنشطة وقيمة الثركة ، الثانيـة وجـود المخـاطر الأخلاقيـة حيث تعمل الإدارة علـي الإستفادة مـن مزايـا معرفتهـا

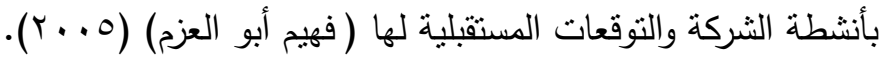

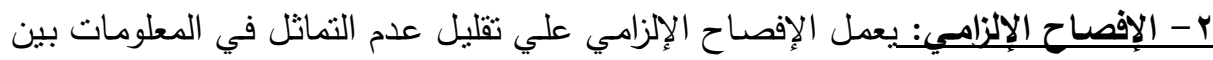

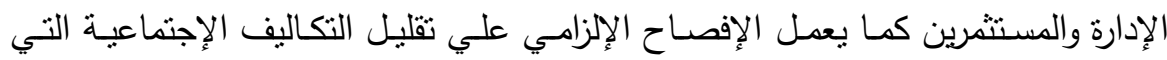
يتحملها المستثمرون للبحث والحصول علي المعلومات (Deegan, C ) (2013). 
معوقـات نظـام الأداء البيئـي: رغم التقدم الذي وقع في مجـال وضـع إطـار متكامـل

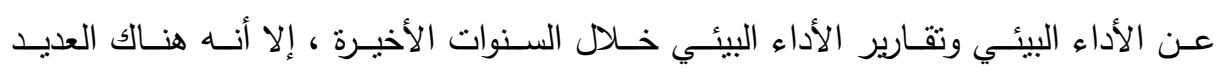

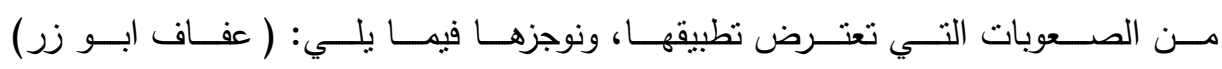
$\cdot(r \cdot v)$ 1-الطبيعـة المختلفــة للنشــاط البيئـي عـن النشــاط الإقتصــادي: إن الــافع مـن وراء

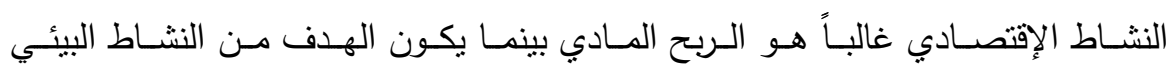

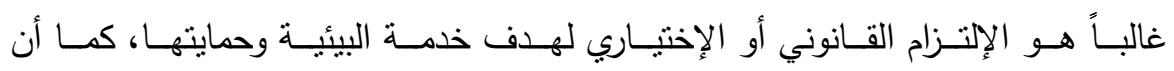

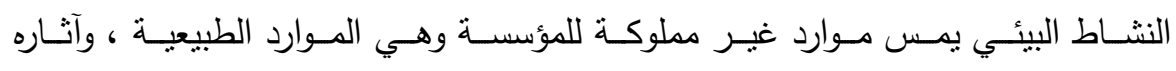
تمس فئات إجتماعية لا نرتبط بعلاقة اقتصادية مع المؤسسة.

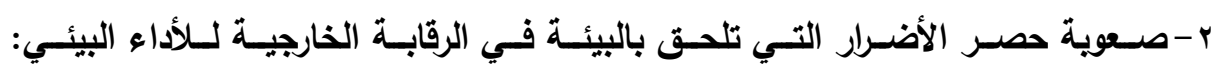

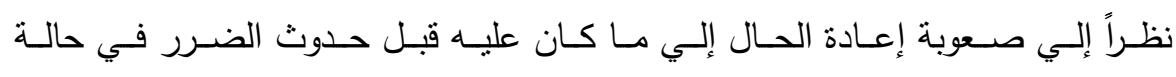

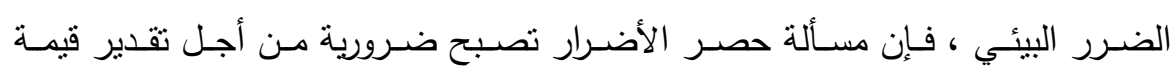
التعويض ، وهي مسألة من الصعب قياسها لأنها تختلف من حالة إلي الأخري.

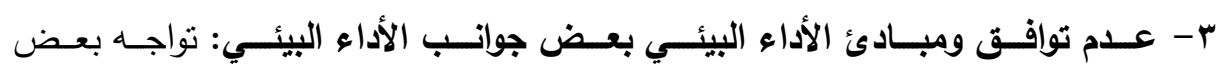

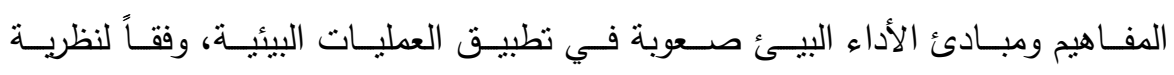

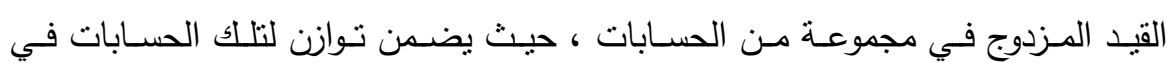

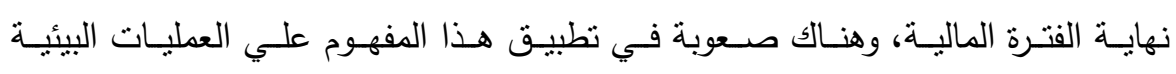
فبعض جوانب الأداء البيئي لا تأخذ صفة الحدث المالي.

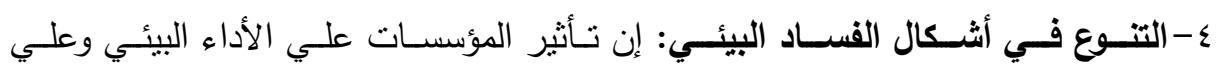

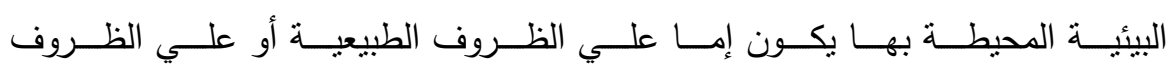

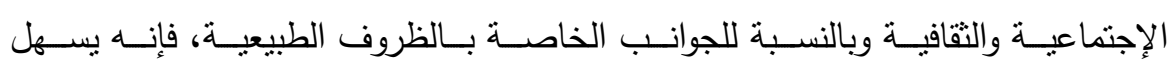

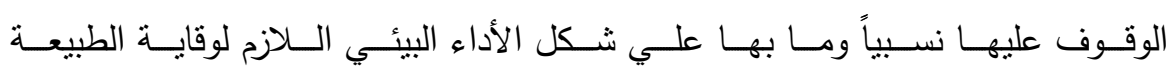
المحيطة من التدهور والفساد واتلوث، وفي عصرنا ولثا لحالي. 
ه-صـعوية قيـاس الأداء البيئسي: إن معظـم الأداء البيئسي هـو عبـاره عـن نفقـات غيـر ملموسة تتمثل بكمية التلوث الناتجة عن المنشأت الصناعية.

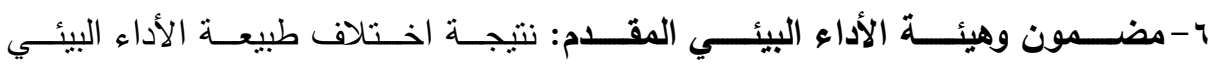

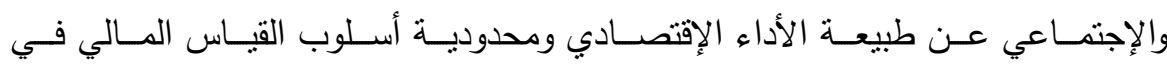
استنفاء قباس مختلف جوانب الآداء البيئي للمؤسسة.

\section{إجبراعاهي وانمائي التواسمة}

الإجـراءات المنهجيـة للاراسـة: إعتمـد البـاحثون علي المنهج الإسـتقرائي الإسـتنباطي للقراءات والأدبيـات للنشـاطات الصـناعية في الثـركات الصـناعية، وقـام البـاحثون بتصـميم إستمارة استقصاء بهدف جمع البيانات وإستطلاع آراء العاملين فى الثركات الصناعيه وقد قام

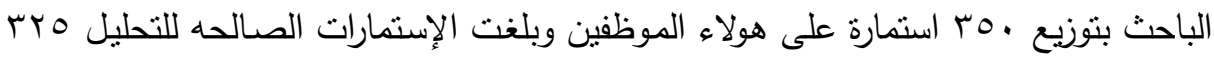
استماره واعتمد الباحث فى جمع بياناته على أسلوب العينه العشوائيه الطبيقه. متغيرات الاراسة ودرجة قياسها المتفير المستقل: إنتاجية الشركات الصناعية المتغير التابع: المؤشرات غير المالية المتغير التابع: المعوقات التى تعرقل قيام الشركات الصناعيه عن الافصاح عن ادائها البيئى المتغير التابع: تحسين الآداء البيئي استخدم الباحث استمارات الإستقصاء قام الباحث بإتباع المنهج العلمى لتصميم إستمارة الإستقصاء، ومر تصميم الإستمارة بعدة مراحل مختلفة من أجل ضبط عملية إعدادها، وتمثلت

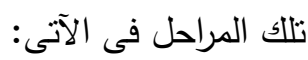
• • تم تحديد بيانات الإستمارة بناء على أهداف الدراسة وتساؤلاتها وفروضها. • تم توزيع عدد 00 استماره كعينة استطلاعية لكل طبقة من طبقات العينة للتأكد من سهولة صياغة الأسئلة ومدى قدرة الأشخاص المستقصى منهم على فهم تلك الأسئلة. 
• بناء على ما تبين من نتائج توزيع استمارات العينة الإسنطلاعية، تم عمل التعديلات

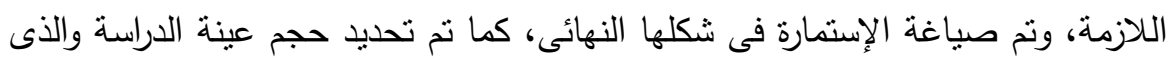

$$
\text { بلغ عددها مبr إستمارة. }
$$

• قام الباحث بإستخدام طريقة المقابلة الثخصية مع الأشخاص المستقصى منهم لجمع إنى

$$
\text { البيانات المتوافرة فى الإستمارة. }
$$

• قام الباحث بتوزيع • • استمارة استقصاء، وبعد تجميع الإستمارات وفحصها تبين وجود

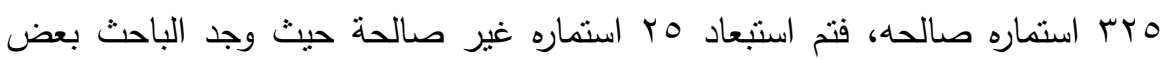
الإستمارات الإجابات فيها غير كاملة والبعض الاخر الإجابات كانت متعارضة، وقد

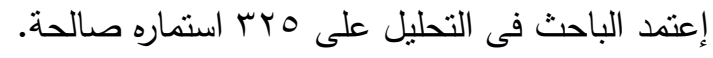

• قام الباحث بتقسيم الإستماره إلى قسمين، القسم الأول بحتوى على المتغيرات الديموجرافيه،

$$
\text { والقسم الثانى يحتوى على المتعبرات التى تعبر عن محاور الدراسة. }
$$

القسم الاول من استمارة الاستقصاء: هذا القسم يتضمن المتغيرات الديموجرافيه وتم صياغتها

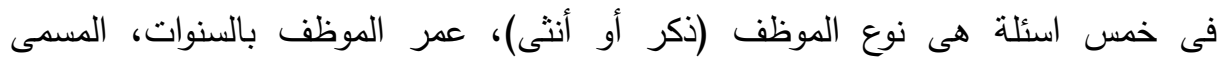
الوظيفى، المؤهل العلمى الحاصل عليه الموظف، ومدة الخبره مقاسه بالسنوات.

\begin{tabular}{|c|c|c|}
\hline رمز المحور & محاور الدراسه & الترتيب \\
\hline Q1 & 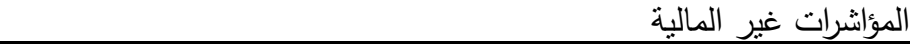 & الاول \\
\hline Q2 & 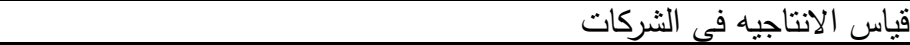 & الثاني \\
\hline Q3 & المعوقات التى تعرقل قيام الثركات الصناعيه عن الافصاح عن ادائها البيئي & الثالث \\
\hline Q4 & الافصاح عن الاداء البئي & الرابع \\
\hline Q5 & تحسين الاداء البيئي & الخامس \\
\hline
\end{tabular}
القسم الثانى من استمارة الاستقصاء: هذا القسم فى استمارة الاستقصاء يحتوى على محاور الدراسة، الجدول التالى يعرض محاور الدراسة ورمز كل محور •

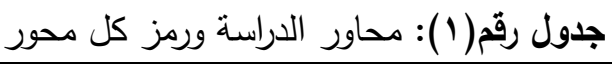

قام الباحث باستخدام برنامج التحليل الإحصائى IBM SPSS الإصدار رقم مب المستخدم فى البحوث الإنسانية والإجتماعية عند تحليل بيانات استمارات الإستقصاء. ولقد فام الباحث بعمل التحليل الإحصائى على اربعة مراحل هى: 
- - اختبار الفا كرومباخ للتحقق من ثبات وموثوقية العبارات الخاصه بكل محور من محاور الدراسه. - تصميم التوزيعات التكرارية لإجابات كل سؤال وذللك للتعرف على طبيعة الإجابات والاتجاه العام لاراء الأشخاص المستقصى منهم. - استخدام مقاييس الإحصاءات الامعلميه لدراسة توزيع مفردات العينه. - استخدام مقاييس الإحصاء الوصفى واختبار (ت) لتعميم نتائج العينه على مجتمع الدراسه.

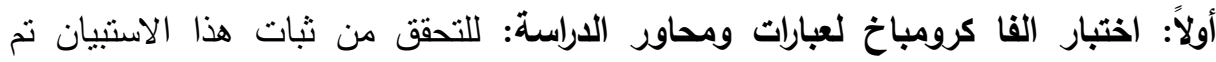
استخدام طريقة الاتساق الداخلي Consistency لعبارات استمارة الاستقصاء، كما تم استخدام طريقة الاتساق الداخلي Consistency لمحاور الدراسه الخمسه، وذللك باستخدام معادلة كرونباخ ألفا Cronbach Alpha ومن المعروف أنه: • اذا كانت قيمة كرونباخ ألفا Cronbach Alpha اكبر من او تسناخ الداخلى ممتاز .

• اذا كانت قيمة كرونباخ ألفا Cronbach Alpha اصغر من 9, · ، واكبر من أو تساوى V, •

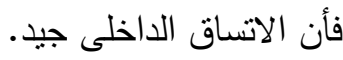

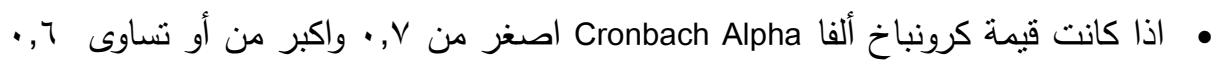
فأن الاتساق الداخلى مقبول.

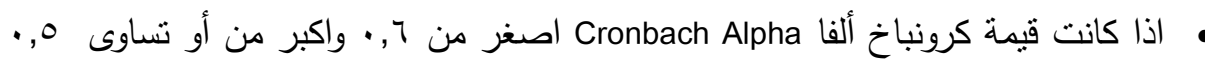
فأن الاتساق الداخلى ضعيف. • اذا كانت قيمة كرونباخ ألفا Cronbach Alpha اصغر من 0, · فأن الاتساق الداخلى غير مقبول. 
جدول رقم(ץ): قيمة معامل كرونباخ الفا لمحاور الدراسه الخمسه وعدد العبارات لكل محور

\begin{tabular}{|c|c|c|c|c|}
\hline عدد عبارات كل محور & الاتساق & كرومباخ الفا & المحاور & \\
\hline 4 & جيد & 0.82 & المؤاشرات غير الماليه & $\mathbf{Q}_{1}$ \\
\hline 9 & جيد & 0.88 & قياس الانتاجيده فى الثركات & $\mathbf{Q}_{2}$ \\
\hline 3 & جيذ & 0.79 & المعوقات & $\mathbf{Q}_{3}$ \\
\hline 11 & جيد & 0.90 & الافصاح عن الاداء البئيي & $\mathbf{Q}_{4}$ \\
\hline 10 & جيد & 0.88 & تحسين الاداء البئيى & $\overline{Q_{5}}$ \\
\hline
\end{tabular}

المصدر: استخراج برنامج spss

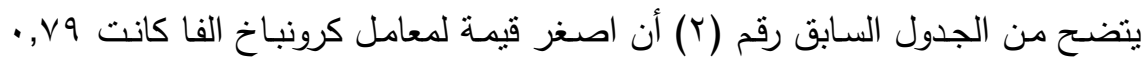

وجاءت للمحور الثالث "المعوقات التى تعرقل قيام الثركات الصناعيه عن الافصاح عن ادائها

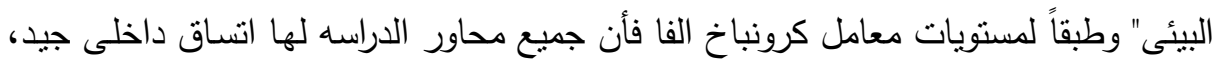
وهذا يعنى امكانية الوثوق فى هذه البيانات فى التحليل الاحصائى وبالتالى فأن الباحث لديه الدليل الاحصائى الكافى بمعامل ثقه 90\% على مصداقية البيانات التى تم جمعها.

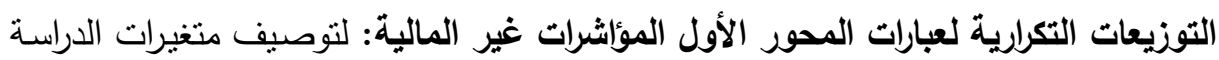

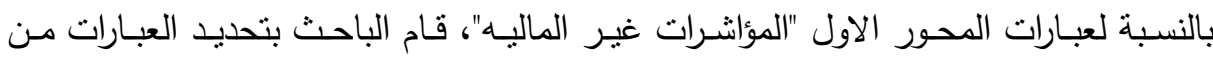
X1 X1 X4 للتعبير عن المحور الاول، وقد تتاولت الدراسة النقاط التالية:

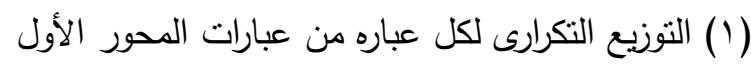

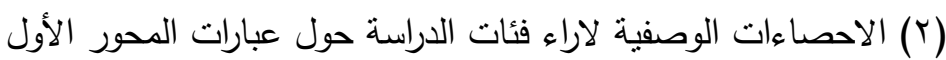

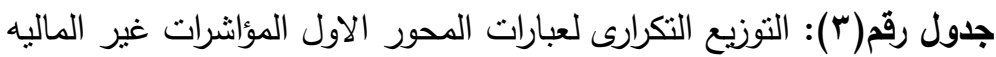

\begin{tabular}{|c|c|c|c|c|c|c|c|c|}
\hline \multicolumn{9}{|c|}{ المحور الاول: الموأشرات غير الماليه } \\
\hline \multicolumn{2}{|c|}{$\mathrm{X} 4$} & \multicolumn{2}{|c|}{$\mathrm{X3}$} & \multicolumn{2}{|c|}{$\mathrm{X} 2$} & \multicolumn{2}{|c|}{ X1 } & رمز العباره \\
\hline النسبه & التكرارات & النسبه & التكرارات & النسبه & التكرارات & النسبه & التكرارات & الاجابه \\
\hline $0.9 \%$ & 3 & $1.5 \%$ & 5 & $0.3 \%$ & 1 & 0 & 0 & رافض بثده \\
\hline $4.0 \%$ & 13 & $2.2 \%$ & 7 & $3.4 \%$ & 11 & $2.5 \%$ & 8 & رافض \\
\hline $13.8 \%$ & 45 & $14.8 \%$ & 48 & $14.2 \%$ & 46 & $15.1 \%$ & 49 & محايد \\
\hline $44.3 \%$ & 144 & $42.8 \%$ & 139 & $43.4 \%$ & 141 & $40.3 \%$ & 131 & موافق \\
\hline $36.9 \%$ & 120 & $38.8 \%$ & 126 & $38.8 \%$ & 126 & $42.2 \%$ & 137 & موافق بشده \\
\hline $100 \%$ & 325 & $100 \%$ & 325 & $100 \%$ & 325 & $100 \%$ & 325 & الاجمالى \\
\hline
\end{tabular}


من جدول رقم (ץ) ينضح ما يلى: بالنسبة للمتغير XI والذى يخص العباره "يعتبر الإلتزام بالتشريعات والقوانين واللوائح البيئة من الضروريات التى لا يمكن مخالفتها وتؤثئر إيجابياً

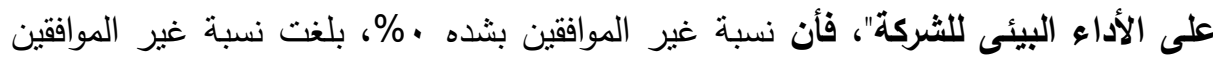

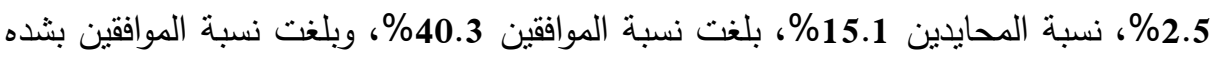
42.2\%، اى ان حوالى ما يقرب من 82\% من اراء فئات الدراسة تميل الى الموافقة والموافقة

\section{اختبارات النتائج والمقاييس الإحصاءات الامعلمية:}

للتعرف على اتجـاه آراء افراد العينة فى الأسئلة التى وجهت اليهم من خـلال استمارة

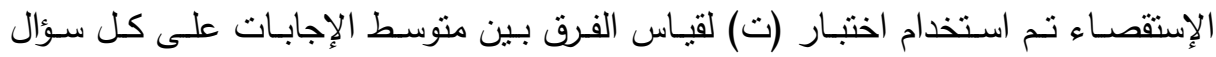

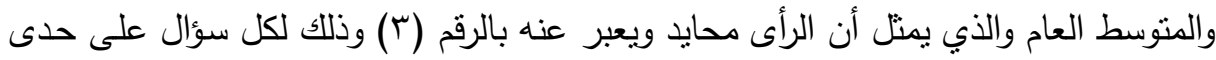
ثم لمجموعة المتغيرات التجميعيه والتى تعبر عن محاور الدراسه هذا الإختبار يستخدم لقياس الفرق بين متوسط الإجابة والمتوسط العام ويحدد ما إذا كان هذا الفرق جوهرى أم انه يرجع إنه

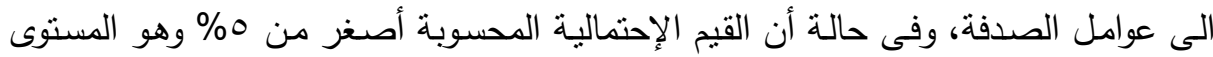
المعنوى النظرى المستخدم فى الأبحاث الإجتماعية فهذا يعنى أنه يوجد اختلاف جوهرى بين الإنها لهنه

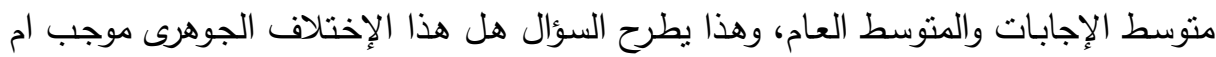

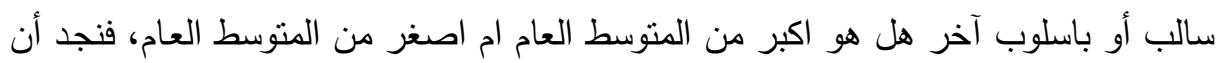

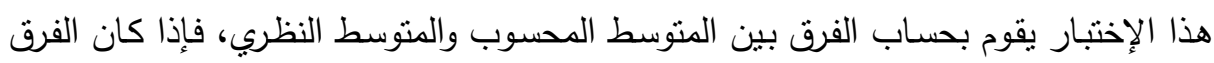
موجب فهذا يعنى أن متوسط الإجابات على هذا السؤال أكبر من المتوسط أى أن مفردات

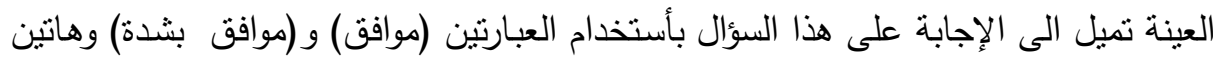

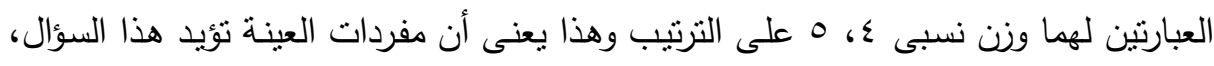
أمسا إذا كان الفرق سالب فهذا يعنى أن مفردات العينة تميل الى الإجابة بأستخدام العبارتين

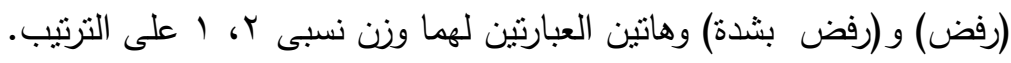


فقد توصـل الباحث الى النتائج الموضـحة بالجدول رقم (·r) الآتى والذى يعرض اسئلة

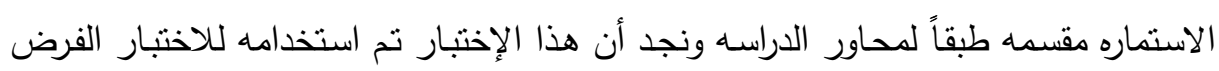
التالى : فرص:

فرض العدم: متوسط الإجابات يساوى المتوسط العام ؟

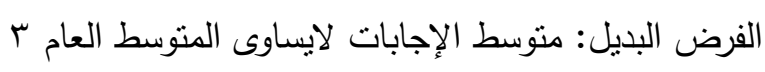

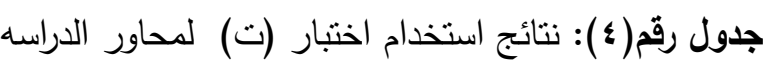

\begin{tabular}{|c|c|c|c|c|}
\hline 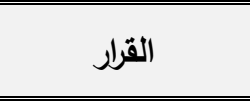 & الاحتماليه & قالمسيوة ت & 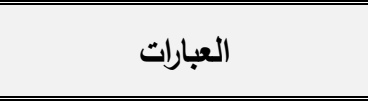 & 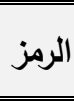 \\
\hline رفض الفرض العدم & 0.000 & 31.355 & المؤاثشرات غير الماليه & $\overline{Q_{1}}$ \\
\hline رفض الفرض العدم & 0.000 & 37.217 & قياس الانتاجيده في الثركات & $Q_{2}$ \\
\hline رفض الفرض العدم & 0.000 & 30.637 & المعوقات & $Q_{3}$ \\
\hline رفض الفرض العدم & 0.000 & 38.116 & الافصاح عن الاداء البئيي & $Q_{4}$ \\
\hline رفض الفرض العدم & 0.000 & 39.963 & تحسين الاداء البئيي & $Q_{5}$ \\
\hline
\end{tabular}

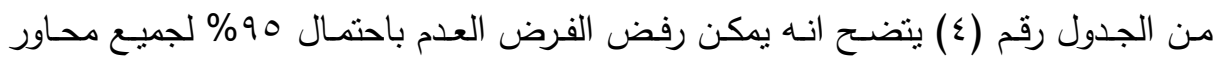

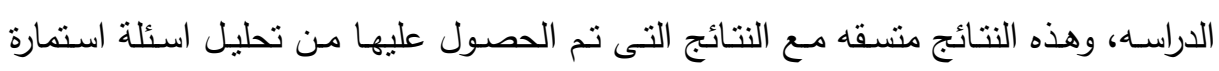

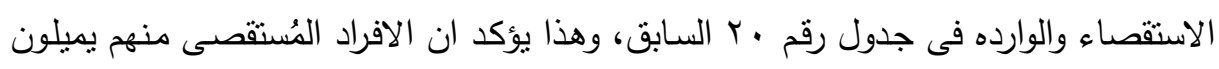
الى الموافقه أو الموافقه بشده على عبارات الاستماره. 
مجلة العلوم البيئية

معهز الدراسات والبحوث البيئية - جامعة عين شمس لهن

جدول رقم(0): مصفوفة الإرنباط بين محاور الدراسة

\begin{tabular}{|c|c|c|c|c|c|c|}
\hline تحسين الاداء & الاداء البئيى عن & المعوقات & الانتاجيه في & المؤاثشرات غير & بيان & محاور الدراسه \\
\hline & & & & 1 & معامل ارتباط & \multirow{2}{*}{ المؤشرات غير } \\
\hline & & & & & الاحتماليه & \\
\hline & & & 1 & 0.609 & معامل ارتباط & \multirow{2}{*}{ في الثركات الانتاجيده } \\
\hline & & & & 0.000 & الاحتماليه & \\
\hline & & 1 & 0.637 & 0.614 & معامل ارتباط & \multirow{2}{*}{ المعوقات } \\
\hline & & & 0.000 & 0.000 & الاحتماليه & \\
\hline & \multirow[t]{2}{*}{1} & 0.705 & 0.721 & 0.718 & معامل ارتباط & \multirow{2}{*}{ 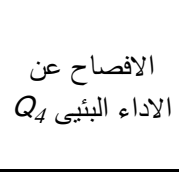 } \\
\hline & & 0.000 & 0.000 & 0.000 & الاحتماليه & \\
\hline \multirow[t]{2}{*}{1} & 0.773 & 0.681 & 0.688 & 0.790 & معامل ارتباط & \multirow{2}{*}{ تحسين الاداء } \\
\hline & 0.000 & 0.000 & 0.000 & 0.000 & الاحتماليه & \\
\hline
\end{tabular}

من جدول رقم (0) يمكن عرض النتائج فى الجدول التالى:

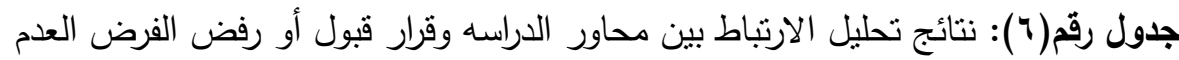

\begin{tabular}{|c|c|c|c|c|c|c|c|}
\hline القرار & الاحتماليه & الارتباط & الرمز & المتغير الثانى & الرمز & المتغز الاول & الفرض \\
\hline العبول العدم & 0.000 & 0.609 & $Q_{2}$ & قالثركات الانتاجيه فى & $Q_{1}$ & المُستخدمه فى تقييم الاداء & الاول \\
\hline الفبول & 0.000 & 0.705 & $Q_{4}$ & $\begin{array}{c}\text { الليئى فى الثركاح عن الاداء } \\
\text { الصناعيه }\end{array}$ & $Q_{3}$ & الالثركات الصناعيه التى تعرقل قيام & الثانى \\
\hline الفبول العدم & 0.000 & 0.773 & $Q_{5}$ & تحسين الاداء البيئى & $Q_{4}$ & فلى الشركات عن الاداء البيئى & الثالث \\
\hline
\end{tabular}

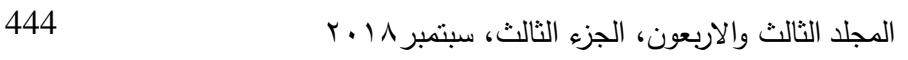


من جدول رقم (ا) يتضح أنه نوجد علاقات جوهريه طرديه بين كل زوج من ازواج

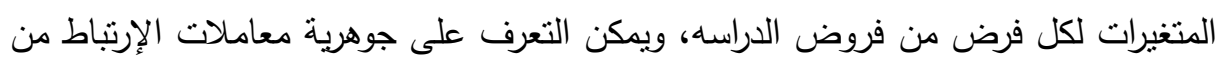

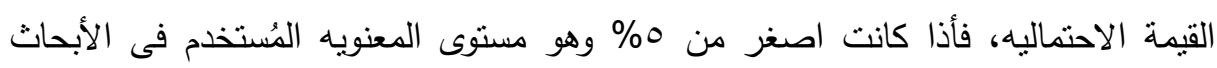

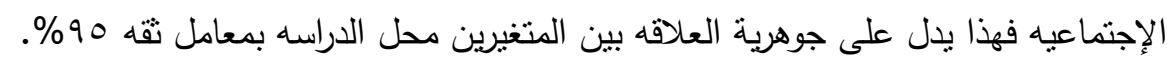

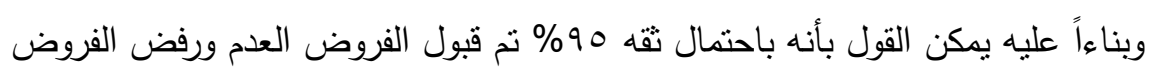

جدول رقم(V): مصفوفة الارتباط بين محاور الدراسة

\begin{tabular}{|c|c|c|c|c|c|c|}
\hline 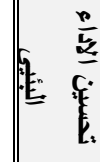 & 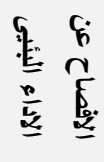 & है & 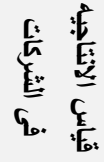 & 点 & بيان & محاور الدراسه \\
\hline & & & & 1 & معامل ارتباط بيرسون & \multirow{2}{*}{ Q1 المؤاثرات غير الماليه } \\
\hline & & & & & القيمه الاحتماليه & \\
\hline & & & 1 & 0.609 & معامل ارتباط بيرسون & \multirow{2}{*}{ Q2 قياس الانتاجيده فى الثركات } \\
\hline & & & & 0.000 & القيمه الاحتماليه & \\
\hline & & 1 & 0.637 & 0.614 & معامل ارتباط بيرسون & \multirow{2}{*}{ Q3 المعوقات } \\
\hline & & & 0.000 & 0.000 & القيمه الاحتماليه & \\
\hline & 1 & 0.705 & 0.721 & 0.718 & معامل ارتباط بيرسون & \multirow{2}{*}{ الافصاح عن الاداء البئيى Q4 } \\
\hline & & 0.000 & 0.000 & 0.000 & القيمه الاحتماليه & \\
\hline 1 & 0.773 & 0.681 & 0.688 & 0.790 & معامل ارتباط بيرسون & \multirow{2}{*}{ تحسين الاداء البئيى } \\
\hline & 0.000 & 0.000 & 0.000 & 0.000 & القيمه الاحتماليه & \\
\hline
\end{tabular}

من جدول رقم (V) يمكن عرض النتائج فى الجدول التالى: 
مجلة العلوم البيئية

معهز الدراسات والبحوث البيئية - جامعة عين شمس لهن

جدول رقم(^): نتائج تحليل الارتباط بين محاور الدراسه وقرار قبول أو رفض الفرض العدم

\begin{tabular}{|c|c|c|c|c|c|c|c|}
\hline القرال & الاحتمائيه & معامل & الرمز & المتغير الثانى & الرمز & المتغر الاول & الفرض \\
\hline قبول الفرض & 0.000 & 0.609 & Q2 & قلشركات الاتتاجيه فى & Q1 & المُشتخدمه في تقييم & الاول \\
\hline قبول الفرض & 0.000 & 0.705 & Q4 & الالبئي فى الثركنات الاداء & Q3 & 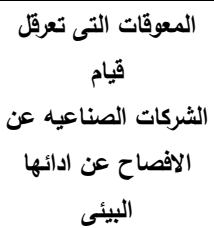 & الثانى \\
\hline قبول الفرض & 0.000 & 0.773 & Q5 & تصسين الاداء البيئي & Q4 & الليئي فى الثركات عنات الأاء & الثالث \\
\hline
\end{tabular}

من جدول رقم (^) يتضح أنه توجد علاقات جوهريه طرديه بين كل زوج من أزواج

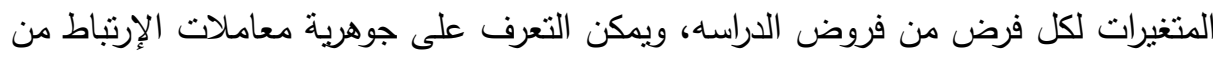

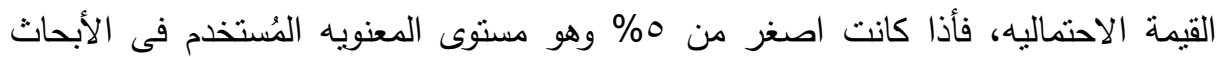

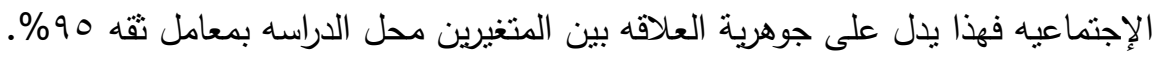

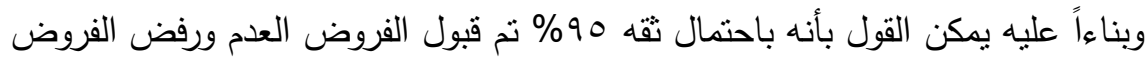
البديله.

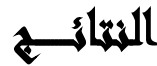

ا-يعتبر الإلتزام بالتشريعات والقوانين واللوائح البيئية من الضروريات التي لا يمكن مخالفتها

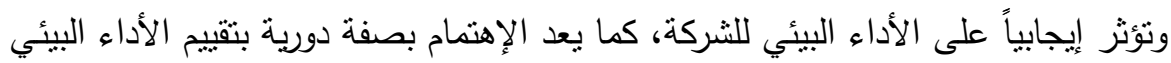
للشركة من الأسباب المؤدية لتحسين وتطوير الأداء البيئي.

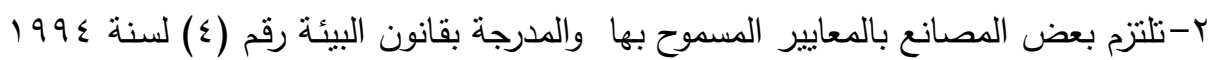
ولكنها لم تلتفت للتعديلات الخاصة بهذا القانون. 
r-أن الأداء البيئي هو ما تقوم به الثركة من أنشطة سواء إجبارية أو إختيارية للحفاظ على

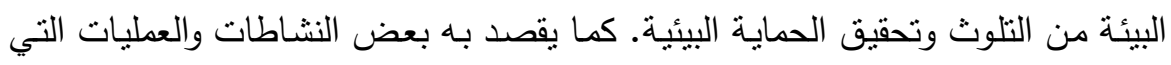
تقوم بها الثركة سواء بشكل إجباري او إختياري والتي من شانها منع الأضرار البيئية او

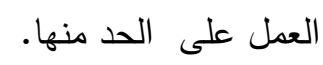

ع - أن الأداء البيئي في الثـركات الصناعية يرتبط بإهنمام الثـركات بالإفصـاح ، كما يرتبط

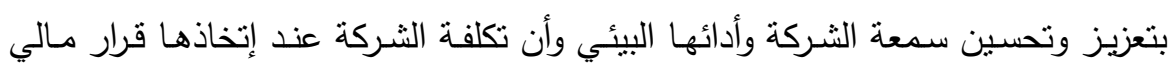
للحفاظ على البيئة بصبح هذا القرار أقل تكلفة بكثير بمقارنته بعدم الإلتزام.

\section{التموعياهت}

هدفت هذه الدراسة بجانبيها النظري والميداني الي إبراز أهية إلتزام الثركات الصناعيه وفي ضوء نتائج الدراسة يوصي الباحثون بما يلي:

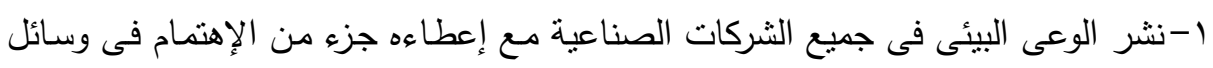

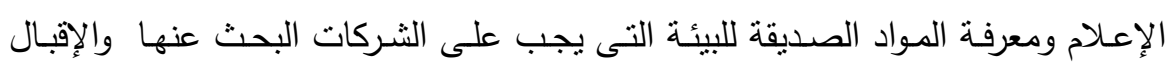
عليها. ץ- نطوير التشريعات (تعديل القوانين والعقوبات) بحيث تتتاسب مع حجم الأضرار وكذلك مع الطبيعة البشرية لتحسين الأداء البيئي.

r- الرقابة الدورية على الشركات الصناعية الملوثة للييئة وتكون بتوجيه صادر من رئاسئة الوزراء على تلاك الشركات فى غير الأوقات الرسمية لإكتثاف المخالفات التى قد تحدث.

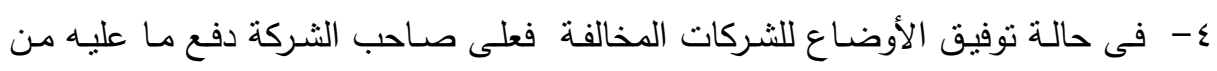
رواتب للعاملين وعليه نشر الوعى البيئى مع توقيع شدة الجزاء.

\section{zall}

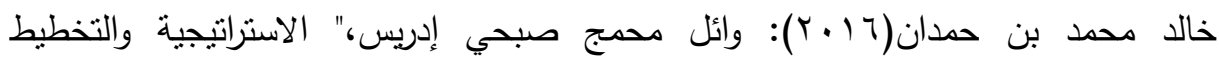

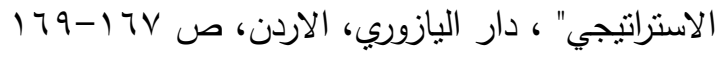

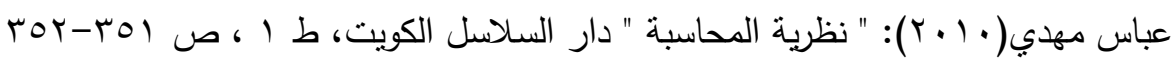


عبد الرزاق قاسم الشحادة: "القياس المحاسبى لتكاليف الأداء البيئى للشركة السورية العامة

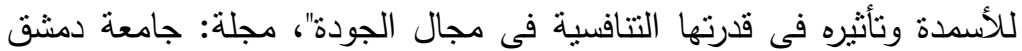

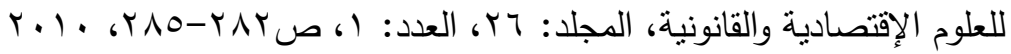

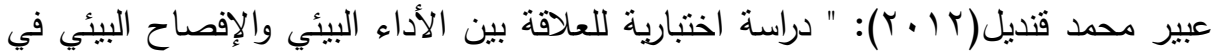

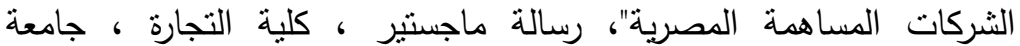

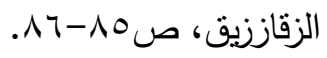

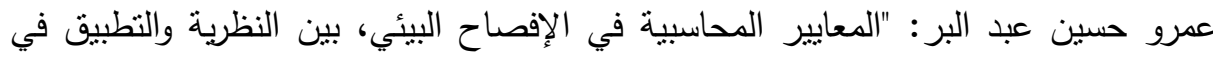

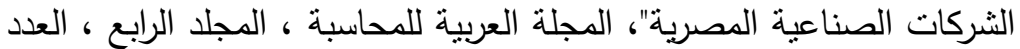

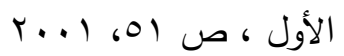

مزغيش عبد الحليح: "تحسين أداء المؤسسة فى ظل إدارة الجودة الثاملة"، رسالة ماجستير،

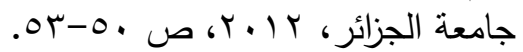

مهوات لعبيدي(10 ب):" القياس المحاسبي للتكاليف البيئية والافصاح عنها في القوائم المالية

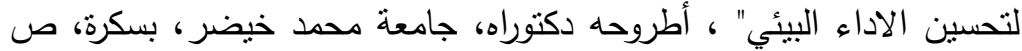

نشوي أحمد الجندي:" استخدام مدخل ترشيد الفاقد في تطوير إسلوب لتكلفة علي اساس النشاط الموجه بالوقت (دراسة تطبيقية)"، مجلة المحاسبة والادارة والتامين ، كلية

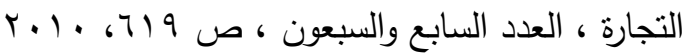

Eddy Bauraing Jacques Nicolas et les autres, Les indicateurs de performances environnementales, Annexe technique, Luxembour UNIVERCITY, 2000,p3.

EU : Integrated Pollution Prevention and Control (IPPC). Reference Document on Best Available Techniques in the Cement and Lime Manufacturing Industries, December 2001.P.60.

Jingjing Wan -Youchun Tang,"Literature Review of Corporate Environmental Performance Evaluation",Volume: 5, Issue:7 , 2014 , PP: 29-34 .

Lowe, I. Globalization, "Environment and Social Justice. Social Alternatives", 23, no.4, 2004, 37-41. 
أحمد سيد عبد الرازق الثريف وآخرون

\title{
A PROPOSED FRAMEWORK TO IMPROVE ENVIRONMENTAL PERFORMANCE AND ITS IMPACT ON PRODUCTIVITY IN INDUSTRIAL COMPANIES
}

\author{
Alsharif, A. S. A. ${ }^{(1)}$; Lotfi, M. A. ${ }^{(2)}$ and Salam, S. H. ${ }^{(2)}$ \\ 1) Institute of Environmental Studies \& Research, Ain Shams \\ University 2) Faculty of Commerce, Ain Shams University
}

\begin{abstract}
This study aimed to identify the improvement of environmental performance and its impact on the productivity of industrial companies to contribute to solving the problems faced by industrial companies to improve their environmental performance.

To achieve this goal, the researchers relied on the theoretical rooting through the inductive method, from books and references, and Arab and foreign studies, And then conduct a field study by designing a survey list of a group of senior managers, internal auditors and auditors, In order to study their views in the impact of environmental improvement on the productivity of industrial companies. Sample Study Industrial Companies, The forms were distributed at the levels of senior management executives, internal auditors and auditors, The researchers distributed 350 survey forms, After the collection and examination of the forms, there were 325 valid forms, Twenty-five invalid forms were excluded. The researcher found some questionnaires incomplete and some of them were conflicting. The researchers relied on 325 valid forms, The study found that there is a fundamental relationship between the non-financial indicators in evaluating performance and measuring productivity in industrial companies. The study recommended increasing awareness and spreading environmental awareness in all industrial companies, while giving them part of the interest in the media and knowledge of the environment friendly materials that companies should search for and attract.
\end{abstract}

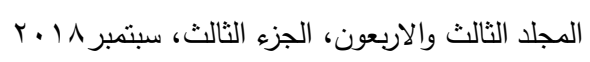

